\title{
Effects of a single high dose of Chlorpyrifos in long-term feeding, ethanol consumption and ethanol preference in male Wistar rats with a previous history of continued ethanol drinking
}

\author{
Francisca Carvajal1,2, Maria del Carmen Sanchez-Amate², José Manuel Lerma-Cabrera1,2 \\ and Inmaculada Cubero1,2 \\ 'Department of Psychology, Universidad Autónoma de Chile, Carlos Antúnez, 1920, Santiago de Chile, Chile \\ ${ }^{2}$ Department of Psychology, Universidad de Almería, Carretera Sacramento s/n, La Cañada, 04120, Almería, Spain
}

(Received March 13, 2014; Accepted April 9, 2014)

\begin{abstract}
Chlorpyrifos (CPF) is an organophosphate compound that is slowly delivered in the organism after subcutaneous injection, keeping acetylcholinesterase (AChE) activity mildly inhibited for weeks. We have previously reported reduced voluntary ethanol drinking 8 weeks post-CPF administration in Wistar rats when AChE activity was almost completely recovered. Additionally, the OPs disrupt the functioning of certain neurochemical systems and modify the formation and/or degradation of some neuropeptides with a known role in regulating voluntary consumption of alcohol. Moreover, chronic ethanol intake significantly alters the regional expression of some of these neurochemical systems. Thus, the present study explored whether a previous history with ethanol consumption modify the disturbance in the voluntary ethanol consumption induced by $\mathrm{CPF}$ administration. For this aim, we measured ethanol consumption in increasing concentrations $(8 \%, 15 \%$ and $20 \% \mathrm{w} / \mathrm{v})$ from 4 days to 8 weeks following a single dose of CPF. Two experiments were carried out; experiment 1 was conducted in ethanol-naïve rats and experiment 2, in animals with a previous history of ethanol drinking before CPF administration. Additionally, food and body weight measures were collected. We report here a significant increase in ethanol consumption and preference at high ethanol concentrations (15\% and 20\%) in CPF-treated animals with a previous history of ethanol consumption (experiment 1) and a long-lasting increase in food intake both in ethanol-exposed (experiment 1) and ethanol-naïve CPF-treated rats (experiment 2). Present data are discussed under the interesting idea that CPF targets neurobiological pathways critically involved with ethanol consumption. Additionally, we conclude that CPF effects on voluntary ethanol consumption are ethanol-experience dependent.
\end{abstract}

Key words: Chlorpyrifos, Organophosphates, Ethanol drinking, Food consumption

\section{INTRODUCTION}

Chlorpyrifos (CPF) is an organophosphate compound (OP) used worldwide in agriculture, industry and households (Pope, 1999; Richardson, 1995). The main mechanism of organophosphates toxicity is acetylcholinesterase (AChE) inhibition (Bushnell et al., 1993) leading to the accumulation of acetylcholine (ACh) at cholinergic synapses, although alternative neurochemical mechanisms have also been described (Casida and Quistad, 2004; Gupta, 2004; Pope, 1999). A single subcutaneous (sc) dose of CPF keeps AChE activity mildly inhibited for weeks (Bushnell et al., 1993), which is indicative of the long-lasting active permanence of the compound and/ or the oxon metabolite in the brain (Bushnell et al., 1993; Richardson, 1995). These unique pharmacokinetic properties might lead to neural adaptations (Pope, 1999) contributing to the emergence of delayed behavioral, emotional and cognitive impairments (Bayrami et al., 2012; Delgado et al., 2004).

Clinical evidence suggests that acute, intermittent or continuous exposure to organophosphate pesticides might

Correspondence: Francisca Carvajal (E-mail: maria.carvajal@uautonoma.cl) 
result in the development of increased sensitivity to drugs of abuse and ethanol (Miller, 2000). Thus, a significant percentage $(60 \%)$ of Gulf War veterans (Miller, 2000) as well as agricultural workers suffering acute organophosphate intoxication developed long-term intolerance to nicotine and ethanol-containing beverages (Tabershaw and Cooper, 1966). Moreover, we reported that Wistar rats administered with a single high dose of the organophosphate CPF exhibit a reduction in voluntary ethanol consumption eight weeks post-administration and increased ethanol sedation, at a time when cerebral AChE activity was mostly recovered (Carvajal et al., 2007).

OPs disrupt the functioning of certain neurotransmitter systems critically involved in ethanol consumption, as the dopaminergic and the cannabinoid system (Gralewicz et al., 2002; Moreno et al., 2008; Quistad et al., 2001, 2002; Rocha et al., 1996; Sanchez-Amate et al., 2002). Three weeks after acute exposure to the chlorphenvinphos OP, behavioural responsiveness to amphetamine and scopolamine (Gralewicz et al., 2002) were reported. In the case of cannabinoid system, chlorpyrifos oxons potentiate the cannabinoid activity of anandamide in mice (Quistad et al., 2001), probably because it inhibits $50 \%$ of the FAAH activity (Quistad et al., 2002; Liu et al., 2013) Also, OPs modify the formation and/or degradation of some neuropeptides (Slotkin and Seidler, 2010) with a known role in voluntary consumption of alcohol (Rada et al., 2004; Schneider et al., 2007; Thiele et al., 2003). Thus, in vitro studies showed that chlorpyrifos evoked a robust upregulation of corticotropin releasing hormone, galanin or neuropeptide Y (Slotkin and Seidler, 2010).

Additionally, several studies showed that chronic ethanol exposure significantly lead to decreased levels of dopamine (Corominas et al., 2007; Smith et al., 2008) and increased levels of endocannabinoids (Basavarajappa and Hungund, 1999; Basavarajappa et al., 2000; Colombo et al., 2002). Besides, levels of orexin mRNA (Morgansterm et al., 2010) and $\alpha$-MSH (Cubero et al., 2010) were reduced and levels of opioid encephalin and galanin were increased (Chang et al., 2007, 2010) by chronic exposure to ethanol.

Bearing in mind the impact of OP on several neurochemical and/or neuromodulators systems, which in turn can be altered by continued ethanol intake, the main objective of this work is to evaluate whether a history of alcohol consumption modifies the effect of CPF on voluntary alcohol consumption previously described in our lab (Carvajal et al., 2007). For that aim, we evaluated ethanol consumption for eight weeks in ethanol pre-exposed and ethanol naïve animals treated with a single high dose of CPF. Additionally, in previous studies we found that CPF altered feeding without an impact on body weight gain (Carvajal et al., 2007) and reduces basal c-fos expression in the arcuate hypothalamic nucleus (Carvajal et al., 2014), a brain region were feeding neuropeptides are produced. Additionally, given these data and that neuropeptides affected by OP and ethanol intake have also an important role in feeding (for a review, see Boughton and Murphy, 2013), we will analyse if CPF alters food intake under experimental conditions used in this study.

\section{MATERIAL AND METHODS}

\section{Animals}

Male Wistar albino rats (Charles River Laboratories, Barcelona, Spain) weighing 300-350 g at the beginning of the experiments were housed individually and maintained in an environmentally controlled room $\left(22^{\circ} \mathrm{C}\right.$ temperature on a 12:12 hr light-dark cycle). Food and water were provided ad libitum. Behavioural procedures and pharmacological techniques were approved by the Bioethical animal care committee at the University of Almeria, Spain. They were in agreement with the animal care guidelines established by the Spanish Royal Decree 1025/2005 for reducing animal pain and discomfort.

\section{CPF administration}

After 15 days of habituation to the laboratory conditions, the animals in experiment 1 were weighed and homogeneously distributed into two groups, CPF group $(\mathrm{n}=16)$, that received a single sc injection of CPF $(\mathrm{O}, \mathrm{O}-$ diethyl-O-[3,5,6-trichloro-2-pyridyl] phosphorothioate, 99.5\%, Riedel-de Haën, Germany, dissolved in olive oil, $250 \mathrm{mg} / \mathrm{kg}$ in $1 \mathrm{ml} / \mathrm{kg})$, and $\mathrm{VEH}$ group $(\mathrm{n}=14)$, that received a sc injection of olive oil $(1 \mathrm{ml} / \mathrm{kg})$ as vehicle. In experiment 2 , following 15 days of habituation to the laboratory conditions and prior to experimental treatment with CPF, animals were exposed for 3 weeks to unlimited 24-hr free access to an ethanol solution ( $8 \% \mathrm{w} / \mathrm{v})$ and water in a two bottle procedure. After continued ethanol consumption for three weeks, the animals were weighed and homogeneously distributed into two groups based on daily averaged ethanol consumption and treated with $\mathrm{CPF}$ $(n=18)$ or vehicle $(n=13)$ as described above. We did not perform a dose-response study for two main reasons. First, the dose of CPF chosen in the study elicits maximum brain AChE inhibition (close to $90 \%$ inhibition 4 days post-poisoning) and keeps AChE mildly inhibited for weeks without overt signs of toxicity; adding additional doses of the compound unnecessary increase the total number of animals in the study; second, although this is a sub-clinical dose, it triggers delayed long-last- 
Chlorpyrifos increases food and ethanol intake in Wistar rats

ing disturbances in ethanol consumption (Carvajal et al., 2007), reduces neural activity (Carvajal et al., 2005, 2007, 2014) and blunts dopaminergic and serotonergic function 30 days post-administration (Moreno et al., 2008).

\section{Voluntary ethanol consumption}

In experiment 1 the animals were exposed for seven weeks to an ethanol-drinking schedule starting four days post-CPF or VEH administration consisting of 24-hr free access to two bottles, one containing plain water and the other containing a solution of ethanol diluted in plain water. Wistar rats usually prefer low ethanol concentrations (6\%-8\%) (Beardsley et al., 1978); however, there is ample evidence showing that pharmacological manipulations of a number of neurochemical systems may enhance voluntary consumption of non-preferred, highly concentrated (15\%-20\%) ethanol solutions that otherwise are spontaneously avoided (Files et al., 1995; Slawecki and Samson, 1997). We tested here whether CPF treatment alters voluntary consumption of two progressively increasing ethanol concentrations. To that end, in experiment $18 \% \mathrm{w} / \mathrm{v}$ ethanol was presented for five weeks, so the animals had the opportunity to stabilize their daily intake, and then ethanol shifted to $15 \% \mathrm{w} / \mathrm{v}$ on weeks 6-8 (see Fig. 1a for temporal details).

In experiment 2 , the animals were pre-exposed to continued $8 \% \mathrm{w} / \mathrm{v}$ ethanol drinking for three weeks before CPF or VEH treatment and then, for two additional weeks post-treatment. Following five weeks of continued $8 \% \mathrm{w} / \mathrm{v}$ ethanol access (matching that in the first study), ethanol was shifted to $15 \% \mathrm{w} / \mathrm{v}$ for two additional weeks. Given that CPF treatment altered voluntary $15 \% \mathrm{w} / \mathrm{v}$ ethanol drinking (see results section), an additional $20 \% \mathrm{w} / \mathrm{v}$ ethanol concentration was tested for two more weeks (see Fig. $1 \mathrm{~b}$ for temporal details).

While animals were exposed to ethanol, the positions of the bottles were changed every two days to control position preferences. In order to obtain a measure of ethanol consumption correcting individual size differences in the rats, the index "g ethanol $/ \mathrm{kg} / 24 \mathrm{hr}$ " was calculated. As a measure of relative ethanol preference, we calculated an ethanol preference ratio by dividing the volume of ethanol solution consumed by the total volume of fluid ( $\mathrm{ml}$ ethanol $+\mathrm{ml}$ water) consumed. In addition, food intake $(\mathrm{g} / \mathrm{kg} / 24 \mathrm{hr})$ and BW (weekly average) were carefully recorded. In all cases, a weekly average of 24-hr consumption/preference measures was calculated for statistical analysis.

\section{Brain acetylcholinesterase determination}

A single dose of CPF $(250 \mathrm{mg} / \mathrm{kg})$ induces a maximum brain AChE inhibition $48 \mathrm{hr}$ post-administration (Cardona et al., 2006; Lopez-Crespo et al., 2007), remaining inhibited at similar extent 4 days post-administration and slowly recovering over a period of approximately twelve weeks (Bushnell et al., 1993). In the present study biochemical indexes of CPF intoxication were collected at two different time-points. Thus, brain AChE inhibition by animals with a previous history of ethanol consumption (EE group) and animals without a previous history of ethanol consumption (EN group) was analyzed four days (when EN group had access to ethanol for first time) and five weeks post-CPF/VEH administration (when altered ethanol consumption was observed) by spectrophotometric methods. For that aim, animals $(n=5)$ in $\mathrm{CPF}$ and VEH groups were randomly selected for cerebral AChE assays. The animals in each group were anesthetized with pentothal sodium $(80 \mathrm{mg} / \mathrm{kg}$ in $1 \mathrm{mg} / \mathrm{kg}$ volume) and then decapitated. The whole brain was removed and immediately homogenized with $1 \%$ Triton X-100 in $0.1 \mathrm{M}$ Na phosphate buffer at $\mathrm{Ph} 8$ at a ratio of $1 / 10$ (wt/ vol). The homogenate was centrifuged at $1,000 \times \mathrm{g}$ for $10 \mathrm{~min}$; then the pellet was discarded and the supernatant was kept for AChE assay. AChE activity was determined
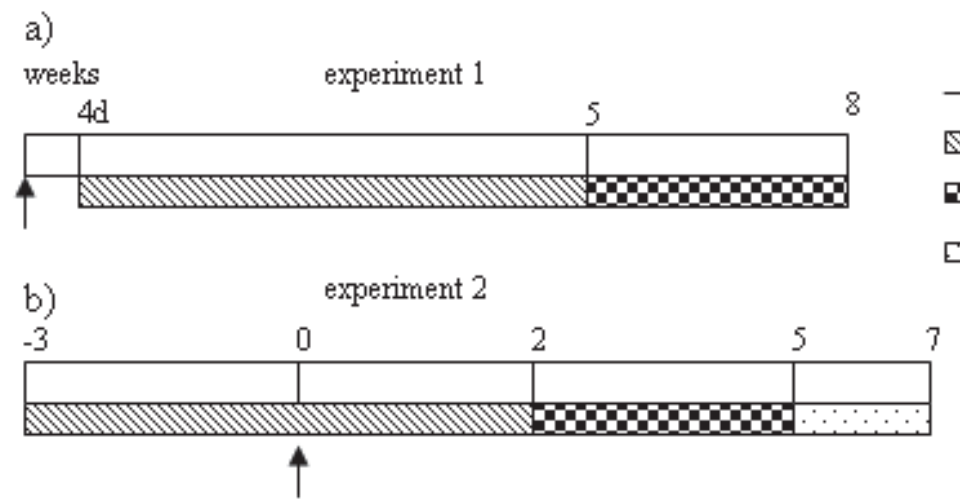

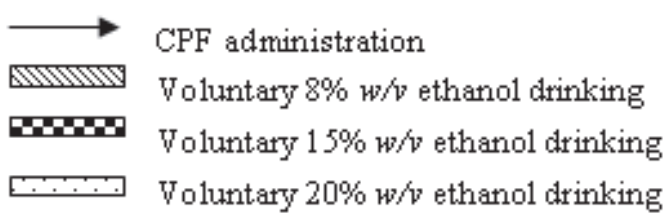

Fig. 1. Schematic representation of time points of experimental testing in experiment 1 (a) and experiment 2 (b). 
by spectrophotometer (DU 530 Beckman spectrophotometer) by the Ellman method (Ellman et al., 1961) using tetraisopropyl pyrophosphoramide (iso-OMPA, specific inhibitors for Butyrylcholinesterase) $(50 \mu \mathrm{l}$; final concentration $50 \mu \mathrm{M})$, acetylthiocholine iodide $(30 \mu \mathrm{l}$; final concentration $0.5 \mathrm{mM}$ ) as substrate and 5,5-dithiobis-2nitrobenzoic acid (DTNB) $(200 \mu \mathrm{l}$; final concentration $0.33 \mathrm{mM}$ ). Assay tubes were completed to $1 \mathrm{ml}$ with $\mathrm{Na}$ phosphate buffer $\mathrm{pH}$ 8. Enzyme activity was calculated relative to protein concentration by the Bradford method (Bradford, 1976). For biochemical assays, acetylthiocoline iodide, iso-OMPA and DTNB were purchased from Sigma-Quimica, Madrid, Spain.

\section{Statistics}

Weekly average ethanol intake (g/kg/24-hr), food intake $(\mathrm{g} / \mathrm{kg} / 24-\mathrm{hr})$ and ethanol preference ( $\mathrm{ml}$ ethanol/ $\mathrm{ml}$ total fluid) data post-treatment were analyzed by independent treatment $\mathrm{x}$ week repeated-measures analysis of variance (ANOVA). Treatment main factor examined differences between CPF and VEH group. Week main factor compared consumption (food, ethanol, fluid), ethanol preference and BW over the testing time; because the week factor did not provide any relevant information for the study, results are not shown. When significant interactions emerged, pair-wise comparisons by post-hoc Newman-Keuls test (NK) were carried out. The accepted level of significance for all tests was $\mathrm{p}<0.05$.

\section{RESULTS}

Effects of CPF exposure on voluntary ethanol consumption, ethanol preference and food consumption in animals without a previous history of ethanol consumption (EN group)

Consumption measures while drinking $8 \% \mathrm{w} / \mathrm{v}$ ethanol solution (weeks 1-5)

Four days post-CPF administration, the animals had 24-hr free access to $8 \% \mathrm{w} / \mathrm{v}$ ethanol solution and plain water for five weeks (see Fig. 1a for temporal details). Independent 2 x 5 (treatment $\mathrm{x}$ week) repeated measures ANOVA were performed on weekly average ethanol, food intake and ethanol preference data obtained over five weeks. The ANOVA conducted on ethanol intake data showed no statistically relevant differences of treatment $(\mathrm{F}(1,19)=0.35 ; \mathrm{p}>0.05)$ or treatment $\mathrm{x}$ week interaction $(\mathrm{F}(4,76)=1.37 ; \mathrm{p}>0.05)$, indicating that CPF treatment did not significantly alter voluntary $8 \% \mathrm{w} / \mathrm{v}$ ethanol consumption relative to VEH treatment (Fig. 2a). In the same direction, the ANOVA conducted on ethanol preference data showed no statistical significance of treatment $(F(1,19)=2.74 ; p>0.05)$ or treatment $x$ week inter- action $(\mathrm{F}(4,76)=1.11 ; \mathrm{p}>0.05)$ (Fig. 2b). The ANOVA conducted to compare food intake in CPF-treated rats relative to $\mathrm{VEH}$-treated rats yielded a significant treatment main effect $(F(1,19)=31.35 ; p<0.01)$ revealing increased food consumption in CPF-treated rats. No significant treatment $\mathrm{x}$ week interaction $(\mathrm{F}(4,76)=1.25$; $\mathrm{p}>0.05$ ) was observed (Fig. 2c).

\section{Consumption measures while drinking $15 \% \mathrm{w} / \mathrm{v}$ ethanol solution (weeks 6-8)}

On weeks 6-8, ethanol concentration was shifted to $15 \% \mathrm{w} / \mathrm{v}$. Weekly average consumption data during this two-week period was analyzed by independent $2 \times 3$ (treatment $x$ week) repeated measures ANOVA. CPF- and VEH-treated animals did not differ in ethanol consumption as revealed by the ANOVA conducted on ethanol intake measures that showed no statistical significance of treatment $(\mathrm{F}(1,19)=1.21 ; \mathrm{p}>0.05)$ or treatment $\mathrm{x}$ week interaction $(\mathrm{F}(2,38)=1.6 ; \mathrm{p}>0.05)($ Fig. $2 \mathrm{~d})$. Additionally, the ANOVA conducted on ethanol preferences data revealed no statistical significance of treatment $(\mathrm{F}(1,19)=0.2 ; \mathrm{p}>0.05)$ or treatment $\mathrm{x}$ week interaction $(\mathrm{F}(2,38)=1.8 ; \mathrm{p}>0.05)($ Fig. 2e). The ANOVA carried out to evaluate food intake while drinking $15 \% \mathrm{w} / \mathrm{v}$ ethanol solution showed no statistical significance of treatment main effect $(\mathrm{F}(1,19)=0.03 ; \mathrm{p}>0.05)$ or treatment $\mathrm{x}$ week interaction $(\mathrm{F}(2,38)=0.5 ; \mathrm{p}>0.05)$ (Fig. 2f).

\section{Body Weight in the EN group}

Weekly average BW data collected for eight weeks post-CPF poisoning in EN rats were analysed by independent $2 \times 8$ (treatment $\mathrm{x}$ week) repeated measures ANOVA that evaluated body weight evolution in CPFand VEH-treated rats for eight weeks. The ANOVA conducted on data showed similar BW in CPF- and VEHtreated rats over this period, treatment $(\mathrm{F}(1,19)=0.4$; $\mathrm{p}>0.05)$, treatment $\mathrm{x}$ week interaction $(\mathrm{F}(7,133)=0.2$; p > 0.05), (Fig. 3).

\section{Effects of CPF exposure on voluntary ethanol consumption, ethanol preference and food consumption in animals with a previous history of ethanol consumption (EE group)}

Consumption measures while drinking $8 \% \mathrm{w} / \mathrm{v}$ ethanol solution (weeks 1-2 post-treatment)

A 2 x 2 (treatment $\mathrm{x}$ week) repeated measures ANOVA performed on weekly averaged ethanol intake data over two weeks showed no statistical significance of treatment $(\mathrm{F}(1,29)=0.2 ; \mathrm{p}>0.05)$. The treatment $\mathrm{x}$ week interaction attained statistical significance, $(\mathrm{F}(1,29)=4.9$; $\mathrm{p}<0.05)$; additional post-hoc NK tests did not reveal sig- 

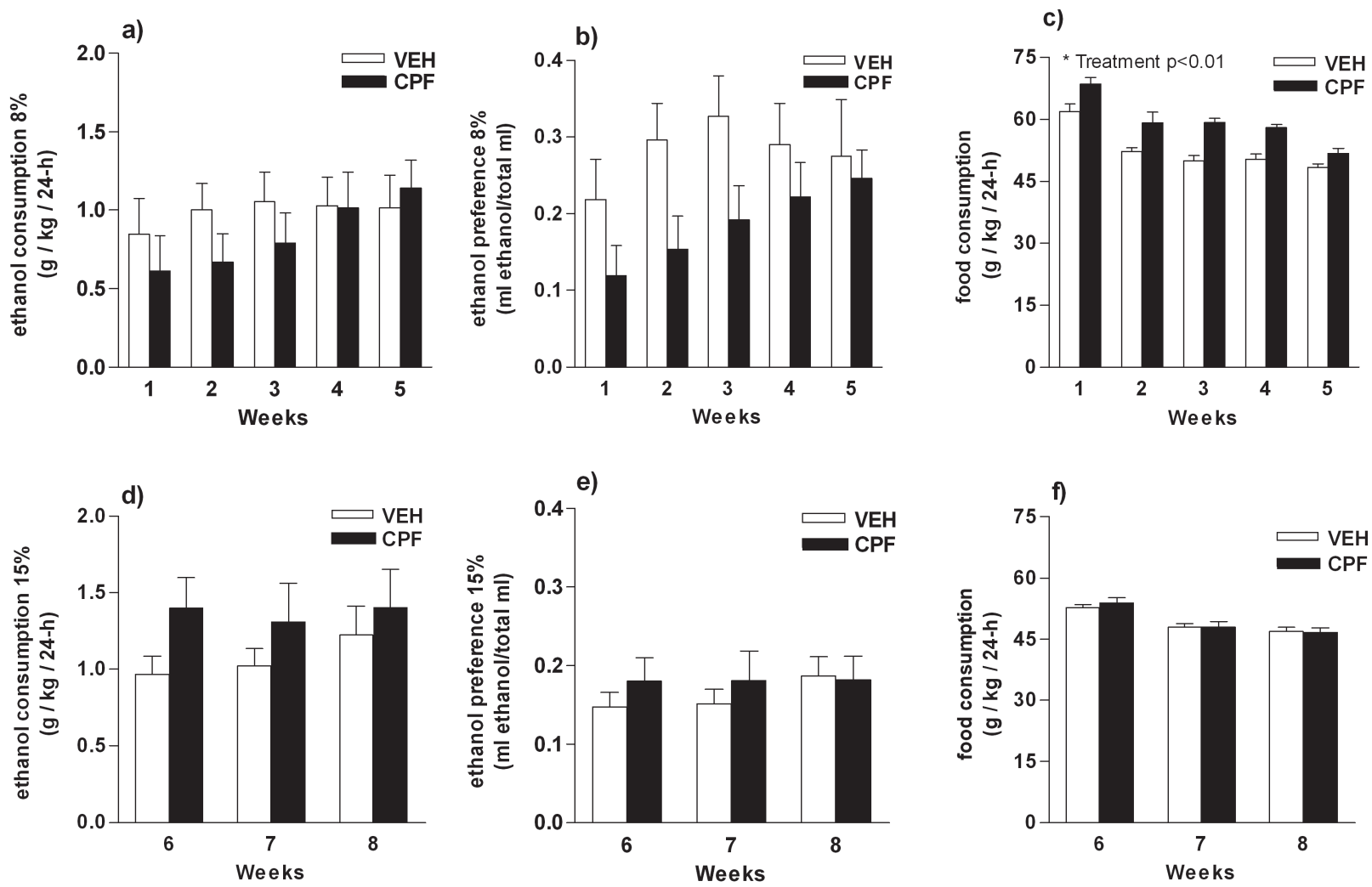

Fig. 2. Graphs represent voluntary consumption of ethanol solutions $(\mathrm{g} / \mathrm{kg} / 24 \mathrm{hr})$, ethanol preference ratio ( $\mathrm{ml}$ ethanol/total $\mathrm{ml})$ and food intake $(\mathrm{g} / \mathrm{kg} / 24 \mathrm{hr}$ ) meanwhile drinking from ethanol solutions, either at $8 \% \mathrm{w} / \mathrm{v}(\mathrm{a}-\mathrm{c})$ or $15 \% \mathrm{w} / \mathrm{v}$ (d-f). The ANOVAs conducted found no significant differences in ethanol consumption/preference in CPF and VEH group. Food intake was significantly increased in CPF-treated animals on weeks 1-5. Values are represented as mean \pm S.E.M.

nificant statistical differences in ethanol intake in CPFand VEH-treated rats at any time-point tested, indicating that $\mathrm{CPF}$ treatment did not significantly alter $8 \% \mathrm{w} / \mathrm{v}$ ethanol drinking relative to VEH treatment (Fig. 4a). The ANOVA conducted to evaluate ethanol preference in CPF- relative to VEH-treated rats while drinking $8 \% \mathrm{w} / \mathrm{v}$ ethanol solution did not show statistical significance of the main factor treatment $(\mathrm{F}(1,29)=0.2$; $\mathrm{p}>0.05)$. The treatment $\mathrm{x}$ week interaction attained statistical significance, $\mathrm{F}(1,29)=6.21 ; \mathrm{p}<0.01)$; however, additional post-hoc analysis showed no significant differences between CPF and VEH in their ethanol preference ratio along the two time-points tested $(\mathrm{NK}>0.05)$ (Fig. 4b). The ANOVA conducted on food consumption data obtained while drinking $8 \% \mathrm{w} / \mathrm{v}$ ethanol solution yielded a significant treatment $\mathrm{x}$ week interaction $(\mathrm{F}(1,29)=8.5 ; \mathrm{p}<0.01)$; however, additional post-hoc NK tests revealed that no significant group differences emerged at any time-point tested (Fig. 4c).

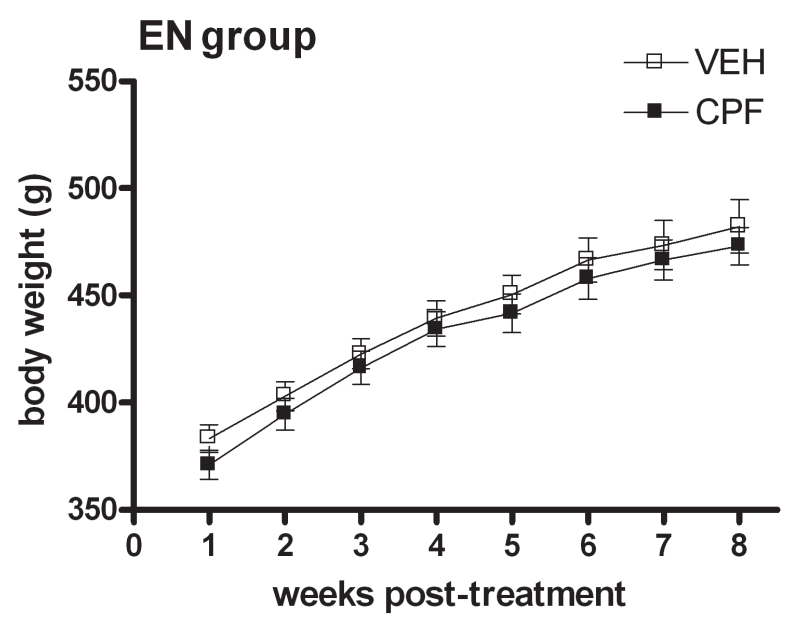

Fig. 3. Graphs represent weekly average BW (g) in EN rats during the testing period ( 8 weeks) while drinking ethanol at different concentrations (8\%: weeks $1-5 ; 15 \%$ : weeks 6-8). No BW differences were found in CPF group relative to VEH group. Values are represented as mean \pm S.E.M. 

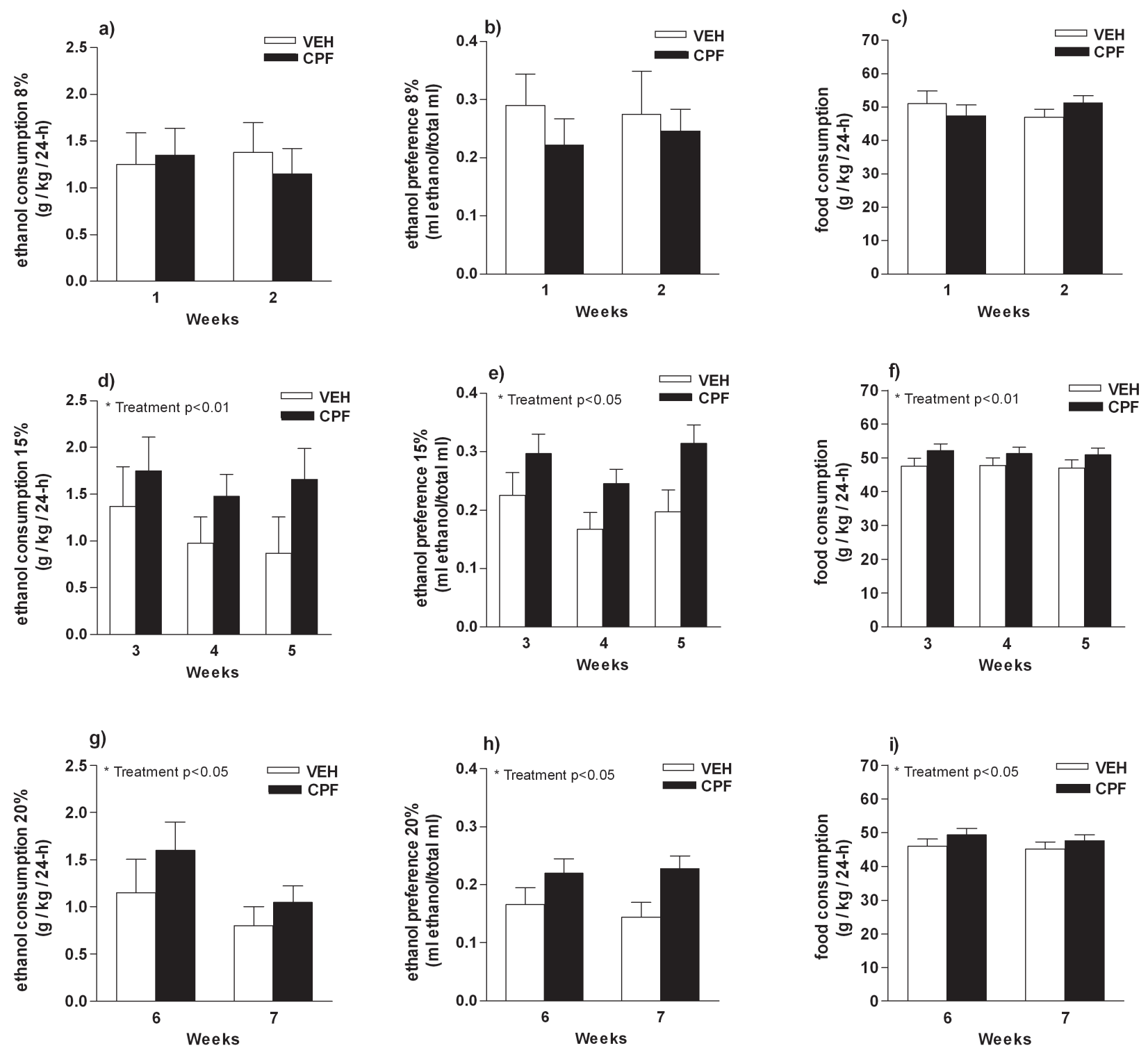

Fig. 4. Graphs represent weekly average voluntary consumption of ethanol solutions $(\mathrm{g} / \mathrm{kg} / 24-\mathrm{hr})$, ethanol preference ratio (ml ethanol $/ \mathrm{ml}$ total fluid) and food consumption ( $\mathrm{g} / \mathrm{kg} / 24-\mathrm{hr}$ ) while drinking $8 \% \mathrm{w} / \mathrm{v}(\mathrm{a}-\mathrm{c}), 15 \% \mathrm{w} / \mathrm{v}$ (d-f) and 20\% w/v (g-i) ethanol solutions. The ANOVAs conducted found increased food intake, ethanol consumption and ethanol preference in $\mathrm{CPF}$ group relative to VEH group while drinking $15 \%$ and $20 \% \mathrm{w} / \mathrm{v}$ ethanol. Values are represented as mean \pm S.E.M.

Consumption measures while drinking $15 \% \mathrm{w} / \mathrm{v}$ ethanol solution (weeks 3-5 post-treatment).

Following five weeks of continued $8 \% \mathrm{w} / \mathrm{v}$ ethanol access, (see Fig. 1b for temporal details), the ethanol concentration was shifted to $15 \% \mathrm{w} / \mathrm{v}$ and additional measures were collected for 3 more weeks. Weekly average consumption data were analyzed by independent 2 x 3 (treatment $x$ week) repeated measures ANO-
VAs. The ANOVA performed on ethanol intake data revealed higher ethanol consumption by CPF-treated rats relative to $\mathrm{VEH}$-treated animals on weeks 3-5 (treatment $(\mathrm{F}(1,29)=8.5 ; \mathrm{p}<0.01)$. The treatment $\mathrm{x}$ week interaction did not attain statistical significance $(\mathrm{F}(2,58)=1.2$; $\mathrm{p}>0.05$ ) (Fig. 4d). The ANOVA conducted on ethanol preference measures revealed that $\mathrm{CPF}$-treated rats displayed significantly higher preference for ethanol con- 
Chlorpyrifos increases food and ethanol intake in Wistar rats

sumption than VEH-treated rats while consuming $15 \% \mathrm{w} / \mathrm{v}$ ethanol solution (treatment $(\mathrm{F}(1,29)=4.1$; $\mathrm{p}<0.05)$. The treatment $\mathrm{x}$ week interaction $(\mathrm{F}(2,58)=$ $2.4 ; \mathrm{p}>0.05)$ did not attain statistical significance (Fig. 4e). Importantly, total fluid consumption (data not shown) in CPF- and VEH-treated rats achieved a similar level, treatment $(\mathrm{F}(1,29)=0.4 ; \mathrm{p}>0.05)$. The ANOVA conducted on food consumption data revealed that CPF-treated rats displayed significantly increased food consumption compared to VEH-treated rats while consuming $15 \%$ $\mathrm{w} / \mathrm{v}$ ethanol on weeks $3-5$, (treatment $(\mathrm{F}(1,29)=7.6$; $\mathrm{p}<0.01)$. The treatment $\mathrm{x}$ week interaction did not attain statistical significance, $(\mathrm{F}(2,58)=2.2 ; \mathrm{p}>0.05)($ Fig. $4 \mathrm{f})$.

Consumption measures while drinking 20\% w/v ethanol solution (weeks 6-7 post-treatment)

On weeks 6-7, the animals were offered 24-hr free access to a $20 \% \mathrm{w} / \mathrm{v}$ ethanol solution and water. Independent $2 \times 2$ (treatment $\mathrm{x}$ week) repeated measures ANOVA were performed on weekly averaged consumption data. The ANOVA conducted on ethanol intake data showed a significant treatment $(\mathrm{F}(1,29)=4.07 ; \mathrm{p}<0.05)$ main effect. The treatment $\mathrm{x}$ week interaction did not attain statistical significance $(\mathrm{F}(1,29)=1.1 ; \mathrm{p}>0.05)$ (Fig. 4g). The ANOVA conducted on ethanol preference measures revealed that $\mathrm{CPF}$-treated rats continued displaying a significantly increased preference for $20 \% \mathrm{w} / \mathrm{V}$ ethanol solution relative to $\mathrm{VEH}$-treated rats, treatment $(\mathrm{F}(1,29)=4.3 ; \mathrm{p}<0.05)$. The treatment $\mathrm{x}$ week interaction $(\mathrm{F}(2,58)=2.4 ; \mathrm{p}>0.05)$ did not attain statistical significance (Fig. 4h). Importantly, the ANOVA performed on total fluid data revealed that CPF- and VEH-treated rats displayed similar rates of total fluid consumption while consuming ethanol at $20 \% \mathrm{w} / \mathrm{v}$, treatment $(\mathrm{F}(1,29)$ $=0.7 ; \mathrm{p}>0.05)$, (data not shown). Finally, the ANOVA performed on food intake data revealed that CPF animals displayed significantly increased food consumption compared to VEH-treated rats while consuming $20 \%$ ethanol over two weeks, treatment $(\mathrm{F}(1,29)=5.2 ; \mathrm{p}<0.05)$. The treatment $\mathrm{x}$ week interaction did not attain statistical significance $(\mathrm{F}(1,29)=1.5 ; \mathrm{p}>0.05)$ (Fig. 4i).

\section{Body Weight in the EE group}

Weekly average body weight data in EE rats collected for seven weeks post-CPF poisoning were analysed by a $2 \times 7$ (treatment $\mathrm{x}$ week) repeated measures ANOVA that compared BW evolution in CPF- and VEH-treated rats. The ANOVA conducted showed a significant treatment $\mathrm{x}$ week interaction, $\mathrm{F}(6,174)=13.6 ; \mathrm{p}<0.01)$ and additional post hoc NK analysis revealed lower BW in CPFtreated rats during the first week of testing. No further significant group differences were found in BW at any time-point tested (Fig. 5).

\section{Temporal Profile of Brain AChE inhibition}

Brain AChE activity in CPF- and VEH-treated rats in the ethanol pre-exposed (EE) and the ethanol-naïve (EN) groups was measured in two parallel groups of randomly selected rats, four days (when AChE inhibition peaks) (Richardson, 1995) and five weeks post-treatment, when altered feeding and ethanol consumption was observed in CPF-treated rats, by independent two-way $2 \times 2$ (treatment $\mathrm{x}$ group) ANOVAs.

\section{AChE inhibition 4 days post-CPF poisoning}

The analysis conducted on AChE data four days posttreatment revealed a statistically significant effect of treatment $(\mathrm{F}(1,16)=101.50 ; \mathrm{p}<0.01)$ in AChE activity: EN group (animals without a previous history of ethanol consumption prior to CPF treatment), CPF $0.0146 \pm$ $0.0055 \mu \mathrm{M} / \mathrm{mg} / \mathrm{min}, \mathrm{VEH} 0.0770 \pm 0.0046 \mu \mathrm{M} / \mathrm{mg} / \mathrm{min}$; EE group (animals with a previous history of ethanol consumption prior to CPF treatment), CPF $0.0153 \pm 0.0022$ $\mu \mathrm{M} / \mathrm{mg} / \mathrm{min}$, VEH $0.0609 \pm 0.0075 \mu \mathrm{M} / \mathrm{mg} / \mathrm{min}$. Thus, AChE activity was $82.04 \%$ and $74.88 \%$ inhibited in the EN and EE groups, respectively (Fig. 6). Neither the group main factor nor the treatment $\mathrm{x}$ group interaction attained statistical significance: $F(1,16)=2.06 ; p>0.05$ and $\mathrm{F}(1,16)=2.45 ; \mathrm{p}>0.05$, respectively.

\section{AChE inhibition five weeks post-CPF poisoning}

The analysis conducted on AChE data five weeks postCPF or VEH treatment revealed a statistically significant effect of treatment, $(\mathrm{F}(1,16)=67.94 ; \mathrm{p}<0.01)$ in AChE activity: EN group, CPF $0.0333 \pm 0.0042 \mu \mathrm{M} / \mathrm{mg} / \mathrm{min}$, VEH $0.0747 \pm 0.0049 \mu \mathrm{M} / \mathrm{mg} / \mathrm{min}$. EE group, CPF 0.0341 $\pm 0.0041 \mu \mathrm{M} / \mathrm{mg} / \mathrm{min}, \mathrm{VEH} 0.0606 \pm 0.0027 \mu \mathrm{M} / \mathrm{mg} /$ min. Thus, AChE activity was $55.43 \%$ and $43.73 \%$ inhibited in the EN and EE groups, respectively (Fig. 6). Neither the group main factor nor the treatment $\mathrm{x}$ group interaction attained statistical significance: $F(1,16)=2.59$; $\mathrm{p}>0.05$ and $\mathrm{F}(1,16)=3.27 ; \mathrm{p}>0.05$, respectively, indicating similar levels of AChE inhibition in the EE and EN groups five weeks post-CPF exposure.

\section{DISCUSSION}

In previous studies, we have demonstrated that exposure to a single high dose of CPF reduces voluntary ethanol consumption eight weeks post-intoxication (Carvajal et al., 2007). The present study was aimed to explore whether a previous history of alcohol consumption mod- 


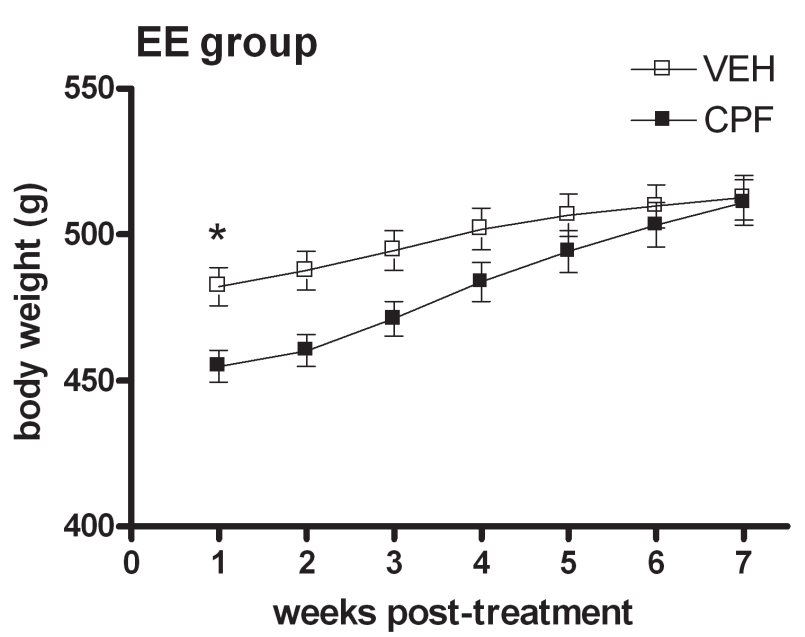

Fig. 5. Graphs represent weekly average BW (g) in EE rats during the testing period (7 weeks) while drinking ethanol at different concentrations (8\% weeks $1-2 ; 15 \%$ weeks 3-5; 20\% weeks 6-7). CPF group reduced BW compared to VEH group on the first week post-treatment (Newman-keuls $\mathrm{p}<0.01)$. No group differences were found on BW during the rest of the testing period (weeks 2-7). Values are represented as mean \pm S.E.M. $* \mathrm{p}<0.01 \mathrm{VEH}$ rats relative to CPF rats.

ifies the effect of CPF on voluntary alcohol consumption reported by our lab (Carvajal et al., 2007).

The first interesting finding in our study is that administration of CPF to animals with a previous history of continued low ethanol drinking caused a delayed and moderate enhancement in voluntary ethanol consumption and ethanol preference compared to VEH-treatment, at high $(15 \%$ and $20 \% \mathrm{w} / \mathrm{v})$ but not low $(8 \% \mathrm{w} / \mathrm{v})$ ethanol concentrations, that lasted for 5 weeks. The observation that total fluid consumption was unaffected rules out unspecific and generalized physiological disturbances in fluid homeostasis as a result of CPF poisoning (data not shown). Importantly, the same dose of CPF administered to animals that were ethanol-naïve at the time of CPF poisoning (EN group) showed moderate but non-significant ethanol avoidance and reduced ethanol preference for 3 weeks. No differences were found in levels of cerebral $\mathrm{AChE}$ inhibition between EE and EN CPF-treated rats, four days and five weeks post-poisoning, clearly suggesting that both groups were exposed to similar levels of the pesticide. Additionally, it indicates that differences in ethanol consumption emerging in ethanol-exposed vs ethanol naïve rats treated with $\mathrm{CPF}$ are unrelated to levels of cerebral AChE inhibition. However, bearing in mind

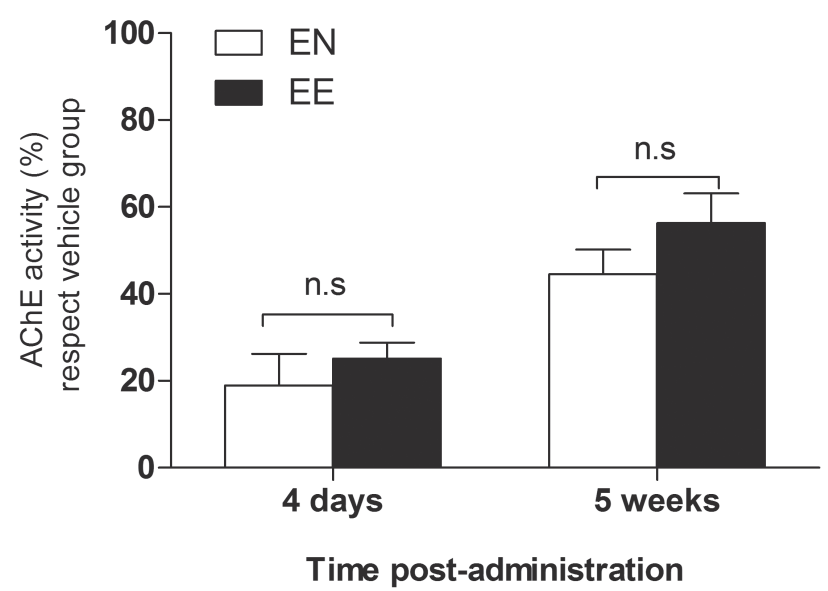

Fig. 6. Graphs showing the percentage (mean \pm S.E.M.) of brain AChE activity in CPF group with (EE group) or without (EN group) a previous history of ethanol consumption respect to levels of enzymatic activity in VEH group, four days and five weeks post-CPF intoxication. CPF administration induced similar levels of AChE inhibition in EN and EE groups, 4 days (EN: $82.04 \%$ inhibition; EE: $74.88 \%$ inhibition) and 5 weeks (EN: $55.43 \%$ inhibition; EE: $43.73 \%$ inhibition) post-administration (n.s: not statistically significative).

recent studies showing variations in AChE-S mRNA and AChE-R mRNA levels after CPF exposure in the absence of changes in the corresponding enzyme activity (LopezGranero et al., 2014), further testing is needed to specifically evaluate this hypothesis. Beside, other enzyme called acylpeptide hydrolase (APH) seems to be more sensitive than AChE to CPF exposure (Cardona et al., 2013), so it could be an alternative mechanism of CPF to study in future research.

The observation that pre-exposure to continued ethanol intakes before CPF administration increases ethanol consumption suggests the interesting hypothesis that alcohol and CPF might share some neurobiological targets. In particular, we discuss briefly two ideas: first, that ethanol and CPF share some metabolic peripheral systems in the liver, and secondly, that ethanol acts on certain neurotransmitter systems and neuromodulators that are also biological targets of CPF. Therefore, both toxics may interact in different biological levels with summative and/or subtractive effects. Thus, the study of different neurobiological and peripheral substrates commons to CPF and ethanol could eventually lead to obtaining predictable profiles of the impact of CPF on voluntary ethanol consumption in the different circumstances of the interaction of OPs with 
Chlorpyrifos increases food and ethanol intake in Wistar rats

exposure to the drug.

In the present study, the effect of CPF on the ethanol consumption is mediated by prior exposure to alcohol in the case of pre-exposed animals. Therefore, chronic ethanol exposure may be affecting neurochemical systems as the dopaminergic or GABAergic (Diaz et al., 2011; Smith et al., 2008), and/or neuromodulators such as the cannabinoid system (Basavarajappa and Hungund, 1999; Basavarajappa et al., 2000) that are also neurobiological targets of CPF. Moreover, both dopaminergic and cannabinoid system have a key role in voluntary ethanol intake (Casu et al., 2002; Colombo et al., 2002; Erdozain and Callado, 2011; Samson et al., 2002). In this regard, several studies showed that chronic exposure to alcohol as the administration of CPF lead to decreased levels of dopamine (Gralewitz et al., 2002; Moreno et al., 2008; Smith et al., 2008) and increased levels of endocannabinoids (Colombo et al., 2002; Liu et al., 2013; Quistad et al., 2001, 2002). Thus, pharmacological manipulations that trigger a decrease in dopamine levels (Izco et al., 2007; Olive et al., 2002; Rassnick et al., 1999) or increased levels of endocannabinoids (Colombo et al., 2002; Erdozain and Callado, 2011) cause an increase in ethanol consumption. Thus, our data of increased alcohol consumption following administration of CPF to animals with a history of ethanol intake may be the result of a summative effect of the effects of CPF administration and chronic ethanol exposure on the dopaminergic and/or cannabinoid system.

On the other hand, we cannot rule out the potential effect of ethanol consumption on metabolic processes shared by ethanol and CPF. Thus, the ethanol can increase the levels of paraoxonase 1 (PON1) (Costa et al., 2005, 2010; Rao et al., 2003), a polymorphic enzyme responsible to hydrolyze the active metabolites of CPF (CPF-oxon) to inactive compounds (Costa et al., 2005; Li et al., 1995). In this way, the existence of a history of alcohol consumption prior to the administration of CPF could be changing metabolic processes that lead to detoxification of organophosphorus compound and consequently its impact on various behaviors, such as the voluntary consumption of alcohol. In fact, several studies using transgenic mouse models founded that paraoxonase plays a key role in modulating the acute toxicity of certain OPs, such as CPF (Cole et al., 2005; Li et al., 2000).

Surprisingly, CPF-treated rats showed enhanced food intake independently of the existence or not of a previous history of ethanol drinking. By other hand, the observation that long-lasting increments in feeding were not followed by significant increments in BW supports that CPF induced a primary energy balance disturbance. The fact that CPF triggered augmented feeding with no changes in BW is consistent with recent experimental evidence showing that neonatal organophosphate exposure causes long-lasting effects on metabolism that might contribute to the development of obesity and diabetes (Lassiter and Brimijoin, 2008; Lassiter et al., 2008; Meyer et al., 2004; Slotkin et al., 2005). In the same direction, chronic exposure to the OP chlorpyrifos (CPF) in adult rats increased body weight gain (Meggs and Brewer, 2007); additionally, CPF triggered a biphasic response in neonates, with enhanced BW gain at low doses, whereas the effect was lost at higher doses (Lassiter and Brimijoin, 2008). Furthermore, neonatal CPF exposure altered the programming of metabolic function (Meyer et al., 2004) and exposure of neonatal rats to parathion elicited sex-selective and dose-dependent metabolic disturbances (Lassiter et al., 2008). Present data add interesting information by suggesting that a single high dose of CPF elicits energy unbalance in adult male rats while drinking ethanol.

In conclusion, the main finding of the present study is that combined pre-exposure to ethanol, voluntarily ingested at not intoxicating doses, and CPF administration have a synergic action to impair voluntary ethanol intake in rats. Thus, the voluntary ethanol preference and ethanol intake was augmented at high ethanol concentrations in adult male CPF-treated rats with a previous history of low ethanol drinking. Importantly, present data provides the first experimental evidence that pre-exposure to chronic ethanol drinking, even at low levels, modulates the effects of CPF on voluntary ethanol intake and ethanol preference. Our present data cannot clarify specific mechanism underlying this effect. However, the search for specific brain system and biochemical mechanism of CPF toxicity underlying the interaction between OP and ethanol would offers a new perspective to these findings pointing to the potential impact of low/moderate social drinking in humans eventually exposed to environmental pollutants such as organophosphates.

\section{ACKNOWLEDGMENTS}

This work was supported by the Spanish grants of Ministerio de Ciencia y Tecnologia [PM//99-1046, SEJ200603629], Junta de Andalucia [CTS-280], and FEDER [UNAM05-23-006].

\section{REFERENCES}

Bayrami, M., Hashemi, T., Malekirad, A.A., Ashayeri, H., Faraji, F. and Adbollahi, M. (2012): Electroencephalogram, cognitive state, psychological disorders, clinical symptom, and oxidative stress in horticulture farmers exposed to organophosphate pesti- 
cides. Toxicol. Ind. Health, 28, 90-96.

Basavarajappa, B.S. and Hungund, B.L. (1999): Chronic ethanol increases the cannabinoid receptor agonist anandamide and its precursor $\mathrm{N}$-arachidonoylphosphatidylethanolamine in SK-NSH cells. J. Neurochem., 72, 522-528.

Basavarajappa, B.S., Saito, M., Cooper, T.B. and Hungund, B.L. (2000): Stimulation of cannabinoid receptor agonist 2-arachidonylglycerol by chronic ethanol and its modulation by specific neuromodulators in cerebellar granule neurons. Biochim. Biophysic. Acta, 1535, 78-86.

Beardsley, P.M., Lemaire, G.A. and Meisch, R.A. (1978): Ethanolreinforced behavior of rats with concurrent access to food and water. Psychopharmacol., 59, 7-11.

Boughton, C.K. and Murphy, K.G. (2013): Can neuropeptides treat obesity? A review of neuropeptides and their potential role in the treatment of obesity. Br. J. Pharmacol., 170, 1333-1348.

Bradford, M.M. (1976): A rapid and sensitive method for the quantitation of microgram quantities of protein utilizing the principle of protein-dye binding. Anal. Biochem., 72, 248-254.

Bushnell, P.J., Pope, C.N. and Padilla, S. (1993): Behavioral and neurochemical effects of acute chlorpyrifos in rats: Tolerance to prolonged inhibition of cholinesterase. J. Pharmacol. Exp. Ther., 266, 1007-1017.

Cardona, D., Lopez-Grancha, M., Lopez-Crespo, G., Nieto-Escamez, F., Sanchez-Santed, F. and Flores, P. (2006): Vulnerability of longterm neurotoxicity of chlorpyrifos: effect on Schedule-induced polydipsia and a delay discounting task. Psychopharmacology, 189, 47-57.

Cardona, D., Lopez-Granero, C., Cañadas, F., Llorens, J., Flores, P., Pancetti, F. and Sanchez-Santed, F. (2013): Dose-dependent regional brain acetylcholinesterase and acylpeptide hydrolase inhibition without cell death after chlorpyrifos administration. J. Toxicol. Sci., 38, 193-203

Carvajal, F., Sanchez-Amate, M.C., Sanchez-Santed, F. and Cubero, I. (2005): Neuroanatomical targets of the organophosphate chlorpyrifos by c-fos immunolabeling. Toxicol. Sci., 84, 360-367.

Carvajal, F., Lopez-Grancha, M., Navarro, M., Sanchez-Amate, M.C. and Cubero, I. (2007): Long-lasting reductions of ethanol drinking, enhanced ethanol-induced sedation, and decreased c-fos expression in the Edinger-Westphal nucleus in Wistar rats exposed to the organophosphate Chlorpyrifos. Toxicol. Sci., 96, 310-320.

Carvajal, F., Lerma-Cabrera, J.M., Sanchez-Amate, M.C. and Cubero, I. (2014): A single high dose of chlorpirifos reduces long-term basal c-fos expression in the rat arcuate hypothalamic nucleus. Int. J. Morphol., 32, 90-96.

Casida, J.E. and Quistad, G.B. (2004): Organophosphate toxicology, safety aspects of nonacetylcholinesterase secondary targets. Chem. Rev. Toxicol., 17, 983-998.

Casu, M.A., Dinucci, D., Colombo, G., Gessa, G.L. and Pani, L. (2002): Reduced DAT- and DBH-immunostaining in the limbic system of Sardinian alcohol-preferring rats. Brain Res., 948, 192-202.

Chang, G.Q., Karatavev, O., Ahsan, R., Avena, N.M., Lee, C., Lewis, M.J., Hoebel, B.G. and Leibowitz, S.F. (2007): Effect of ethanol on hypothalamic opioid peptides, enkephalin, and dynorphin: relationship with circulating triglycerides. Alcohol Clin. Exp. Res., 3, 249-259.

Chang, G.Q., Barson, J.R., Karatayev, O., Chang, S.Y., Chen, Y.W. and Leibowitz, S.F. (2010): Effect of Chronic Ethanol on Enkephalin in the Hypothalamus and Extra-Hypothalamic Areas. Alcohol Clin. Exp. Res., 34, 761-770.
Cole, T.B., Walter, B.J., Shih, D.M, Tward, A.D., Lusis, A.J., Timchalck, C., Richter, R.J., Costa, L.G. and Furlong, C.E. (2005): Toxicity of chlorpyrifos and chlorpyrifos oxon in a transgenic mouse model of the human paraoxonase (PON1) Q192R polymorphism. Pharmacogenet. Genomics, 15, 589-598.

Colombo, G., Serra, S., Brunetti, G., Gomez, R., Melis, S., Vacca, G., Carai, M.M. and Gessa, L. (2002): Stimulation of voluntary ethanol intake by cannabinoid receptor agonists in ethanol-preferring sP rats. Psychopharmacology (Berl), 159, 181-187.

Corominas, M., Roncero, C., Bruguera, E. and Casas, M. (2007): Sistema dopaminérgico y adicciones. Rev. Neurol., 44, 23-31.

Costa, L., Cole, T.B., Vitalone, A. and Furlong, C.E. (2005): Measurement of paraoxonase (PON1) status as a potential biomarker of susceptibility to organophosphate toxicity. Clin. Chim. Acta, 352, 37-47.

Costa, L.G., Giordano, G. and Furlong, C.E. (2011): Pharmacological and dietary modulators of paraoxonase 1 (PON1) activity and expression: the hunt goes on. Biochem. Pharmacol., 81, 337-344.

Cubero, I., Navarro, M., Carvajal, F., Lerma-Cabrera, J.M. and Thiele, T.E. (2010). Ethanol-induced increase of agouti-related protein (AgRP) immunoreactivity in the arcuate nucleus of the hypothalamus of C57BL/6J, but not $129 / \mathrm{SvJ}$, inbred mice. Alcohol Clin. Exp. Res., 34, 693-701.

Delgado, E., McConnell, R., Miranda, J., Keifer, M., Lundberg, I., Partanen, T. and Wesseling, C. (2004): Central nervous system effects of acute organophosphate poisoning in a two-year follow-up. Scand. J. Work Environ. Health, 30, 362-370.

Diaz, M.R., Christian, D.T., Anderson, N.J. and McCool, B.A. (2011): Chronic ethanol and withdrawal differentially modulate lateral/basolateral amygdala paracapsular and local GABAergic synapses. J. Pharmacol. Exp. Ther., 337, 162-170.

Ellman, G.L., Coutney, K.D., Andres, V.J. and Featherstone, R.M. (1961): A new and rapid colorimetric determination of acetylcholinesterase activity. Biochem. Pharmacol., 7, 88-95.

Erdozain, A.M. and Callado, L.F. (2011): Involvement of the endocannabinoid system in alcohol dependence: the biochemical, behavioral and genetic evidence. Drug Alcohol Depend., 117, 102-110.

Files, F.J., Samson, H.H. and Brice, G.T. (1995): Sucrose, ethanol, and sucrose/ethanol reinforced responding under variable-interval schedules of reinforcement. Alcohol Clin. Exp. Res., 19, 1271-1278.

Gralewicz, S., Lutz, P. and Tomas, T. (2002): Behavioural responsiveness to amphetamine or scopolamine following repeated exposure to chlorphenvinphos in rats. Acta Neurobiol. Exp., 62, 75-83.

Gupta, R.C. (2004): Brain regional heterogeneity and toxicological mechanisms of organophosphates and carbamates. Toxicol. Mech. Methods, 14, 103-143.

Izco, M., Marchant, I., Escobejo, I., Peraile, I., Delgado, M., Higuera-Matas, A., Olias, O., Ambrosio, E., O'Shea, E. and Colado, M.I. (2007): Mice with decreased cerebral dopamine function following a neurotoxic dose of MDMA (3,4-methylenedioxymethamphetamine, "Ecstasy") exhibit increased ethanol consumption and preference. J. Pharmacol. Exp. Ther., 322, 1003-1012.

Lassiter, T.L. and Brimijoin, S. (2008): Rats gain excess weight after developmental exposure to the organophosphorothionate pesticide, chlorpyrifos. Neurotoxicol. Teratol., 30, 125-130.

Lassiter, T.L., Ryde, I.T., Mackillop, E.A., Brown, K.K., Levin, E.D., Seidler, F.J. and Slotkin, T.A. (2008): Exposure of neonatal 
Chlorpyrifos increases food and ethanol intake in Wistar rats

rats to parathion elicits sex-selective reprogramming of metabolism and alters the response to a high-fat diet in adulthood. Environ. Health Perspect., 116, 1456-1462.

Li, W.F., Furlong, C.E. and Costa, L. (1995): Paraoxonase protects against chlorpyrifos toxicity in mice. Toxicol. Lett., 76, 219226.

Li, W., Costa, L.G., Richter, R.J., Hagen, T., Shih, D.M., Tward, A., Lusis, A.J. and Furlong, C.E. (2000): Catalytic efficiency determines the in-vivo efficacy of PON1 for detoxifying organophosphorus compounds. Pharmacogenetics, 10, 767-779.

Liu, J., Parsons, L. and Pope, C. (2013): Comparative effects of parathion and chlorpyrifos on extracellular endocannabinoid levels in rat hippocampus: influence on cholinergic toxicity. Toxicol. Apll. Pharmacol., 272, 608-615.

Lopez-Crespo, G.A., Carvajal, F., Flores, P., Sanchez-Santed, F. and Sanchez-Amate, M.C. (2007): Time course of biochemical and behavioural effects of a single high dose of chlorpyrifos. Neurotoxicology, 28, 541-547.

Lopez-Granero, C., Cardona, D., Gimenez, E., Lozano, R., Barril, J., Aschner, M., Sanchez-Santed, F. and Cañadas, F. (2014): Comparative study on short- and long-term behavioral consequences of organophosphate exposure: relationship to AChE mRNA expression. Neurotoxicology, 40, 57-64.

Meggs, W.J. and Brewer, K.L. (2007): Weight gain associated with chronic exposure to chlorpyrifos in rats. J. Med. Toxicol., 3, 89-93.

Miller, C.S. (2000): Toxicant-induced loss of tolerance. Addiction, 96, 115-139.

Meyer, A., Seidler, F.J., Aldridge, J.E., Tate, C.A., Cousins, M.M. and Slotkin, T.A. (2004): Critical periods for chlorpyrifos-induced developmental neurotoxicity: alterations in adenylyl cyclase signaling in adult rat brain regions after gestational or neonatal exposure. Environ. Health Perspect., 112, 295-301.

Moreno, M., Cañadas, F., Cardona, D., Suñol, C., Campa, L., Sanchez-Amate, M.C., Flores, P. and Sanchez-Santed, F. (2008): Long-term monoamine changes in the striatum and nucleus accumbens alter acute chlorpyrifos exposure. Toxicol. Lett., 176, 162-167.

Morganstern, I., Chang, G.Q., Barson, J.R., Ye, Z., Karatayev, O. and Leibowitz, S.F. (2010): Differential Effects of Acute and Chronic Ethanol Exposure on Orexin Expression in the Perifornical Lateral Hypothalamus. Alcohol Clin. Exp. Res., 34, 886896.

Olive, M.F., Nannini, M.A., Ou, C.J., Koenig, H.N. and Hodge, C.W. (2002): Effects of acute acamprosate and homotaurine on ethanol intake and ethanol-stimulated mesolimbic dopamine release. Eur. J. Pharmacol., 437, 55-61.

Pope, C.N. (1999): Organophosphorus pesticides: Do they all have the same mechanism of toxicity? J. Toxicol. Environ. Health B Crit. Rev., 2, 161-181.

Quistad, G.B., Nomura, D.K., Sparks, S.E., Segall, Y. and Casida, J.E. (2002): Cannabinoid CB1 receptor as a target for chlorpyrifos oxon and other organophosphorus pesticides. Toxicol. Lett., 135, 89-93.

Quistad, G.B., Sparks, S.E. and Casida, J.E. (2001): Fatty acid amide hydrolase inhibition by neurotoxic organophosphorus pesticides. Toxicol. App. Pharmacol., 173, 48-55.

Rada, P., Avena, N.M., Leibowitz, S.F. and Hoebel, B.G. (2004): Ethanol intake is increased by injection of galanin in the paraventricular nucleus and reduced by a galanin antagonist. Alcohol, 33, 91-97.

Rao, M.N., Marmillot, P., Gong, M., Palmer, D.A., Seeff, L.B., Strader, D.B. and Lakshman, M.R. (2003): Light, but not heavy alcohol drinking, stimulates paraoxonase by upregulating liver mRNA in rats and humans. Metabolism, 52, 1287-1294.

Rassnick, S., Pulvirenti, L. and Koob, G.F. (1999): SDZ-205,152, a novel dopamine receptor agonist, reduces oral ethanol self-administration in rats. Alcohol, 10, 127-132.

Richardson, R.J. (1995): Assessment of the neurotoxic potential of chlorpyrifos relative to other organophosphorus compounds: a critical review of the literature. J. Toxicol. Environ. Health, 44, 135-165.

Rocha, E.S., Swanson, K.L., Aravaca, Y., Goolsby, J.E., Maelicke, A. and Alburquerque, E.X. (1996): Paraoxon: Cholinesterase-independent stimulation of transmitter release and selective block of ligand-gated ion channels in cultured hippocampal neurons. J. Pharmacol. Exp. Ther., 278, 1175-1187.

Samson, H.H., Tolliver, G.A., Haraguchi, M. and Hodge, C.W. (2002): Alcohol self-administration: role of mesolimbic dopamine. Ann. N. Y. Acad. Sci., 654, 242-253.

Sanchez-Amate, M.C., Dávila, E., Cañadas, F., Flores, P. and Sanchez-Santed, F. (2002): Chlorpyrifos shares stimulus properties with pentylenetetrazol as evaluated by an operant drug discrimation task. Neurotoxicology, 23, 795-803.

Schneider, E.R., Rada, P., Darby, R.D., Leibowitz, S.F. and Hoebel, B.G. (2007): Orexigenic Peptides and Alcohol Intake: Differential Effects of Orexin, Galanin, and Ghrelin. Alcoholism Clin. Exp. Res., 31, 1858-1865.

Smith, J.E., Co, C., McIntosh, S. and Cunningham, C.C. (2008): Chronic binge-like moderate ethanol drinking in rats results in widespread decreases in brain serotonin, dopamine, and norepinephrine turnover rates reversed by ethanol intake. J. Neurochem., 105, 2134-2155.

Slawecki, C.J. and Samson, H.H. (1997): Changes in oral ethanol self-administration patterns resulting from ethanol concentration manipulations. Alcohol Clin. Exp. Res., 21, 1144-1149.

Slotkin, T.A., Brown, K.K. and Seidler, F.J. (2005): Developmental exposure of rats to chlorpyrifos elicits sex-selective hyperlipidemia and hyperinsulinemia in adulthood. Environ. Health Perspect., 113, 1291-1294.

Slotkin, T.A. and Seidler, F.J. (2010): Diverse neurotoxicants converge on gene expression for neuropeptides and their receptors in an in vitro model of neurodifferentiation: effects of chlorpyrifos, diazinon, dieldrin and divalent nickel in PC12 cells. Brain. Res., 1353, 36-52.

Tabershaw, I. and Cooper, C. (1966): Sequelae of acute organic phosphate poisoning. J. Ocupp. Med., 8, 5-20.

Thiele, T.E., Navarro, M., Sparta, D.R., Fee, J.R., Knapp, D.J. and Cubero, I. (2003): Alcoholism and obesity: overlapping neuropeptide pathways? Neuropeptides, 37, 321-337. 